\title{
Use of Short Messaging Service to Improve Follow-Up for Abnormal Pap Test Results in Minority and Medically Underserved Women in North Carolina: Questionnaire on Attitudes and Acceptability
}

LaHoma Smith Romocki ${ }^{1}$, MPH, PhD; Andrea Des Marais ${ }^{2}$, MPH; Leslie Cofie ${ }^{3}$, MA, MPH, PhD; Chelsea Anderson ${ }^{2}$, MPH; Theresa Curington ${ }^{4}$, BSPH; Jennifer Susan Smith ${ }^{2}$, MPH, PhD

${ }^{1}$ Department of Public Health Education, North Carolina Central University, Durham, NC, United States

${ }^{2}$ Department of Epidemiology, Gillings School of Global Public Health, University of North Carolina at Chapel Hill, Chapel Hill, NC, United States

${ }^{3}$ Department of Health Education and Promotion, East Carolina University, Greenville, NC, United States

${ }^{4}$ School of Medicine, Duke University, Durham, NC, United States

\section{Corresponding Author:}

LaHoma Smith Romocki, MPH, PhD

Department of Public Health Education

North Carolina Central University

1801 Fayetteville Street

Durham, NC, 27707

United States

Phone: 19195306404

Fax: 19195307985

Email: 1romocki@nccu.edu

\begin{abstract}
Background: An estimated one in eight cervical cancer cases are due to a lack of follow-up care for abnormal Pap test results. Low rates of completion of follow-up care particularly affect low-income minority women. The burden of cervical cancer could be reduced through interventions that improve timely colposcopy follow-up and treatment of abnormal screening results. Mobile communications via text messaging present a low-cost opportunity to increase rates of clinic return among women referred to follow-up after obtaining abnormal screening results.

Objective: Our aims were to determine the acceptability and feasibility of using text messaging to increase completion of follow-up care following abnormal cervical cancer screening (Pap test) results and to examine factors that may affect the acceptability and use of text messaging to increase communications between health care providers (HCP) and low-income minority women.

Methods: The study participants were 15 low-income women who had undergone a Pap test within the preceding 12 months. Semistructured interviews, including open- and closed-ended questions from a validated questionnaire, were conducted by phone or in person. Responses to closed-ended survey items were tabulated, and descriptive statistics were generated using Microsoft Excel. Responses to the open-ended questions were coded and analyzed using NVivo 11 qualitative analysis software.

Results: Nearly all participants $(14 / 15,93 \%)$ were comfortable receiving a text message from an HCP stating that their Pap test results were available $(<40$ years: $100 \% ; \geq 40$ years: $86 \%)$. Over half $(8 / 15 ; 53 \%)$ of the participants were comfortable receiving a text message stating that their Pap test results were abnormal, although many preferred to receive such information via a phone call $(6 / 15 ; 40 \%)$. Most participants $(9 / 15 ; 60 \%)$ believed that receiving a text reminder would make them more likely to attend their appointment. The preferred method for receiving a reminder appeared to vary by age, with older women preferring telephone reminders over text messaging reminders. Analysis of open-ended questions suggested that text messaging appeals to some women due to its wide use and convenience for communicating with HCPs. However, women cited concerns about the confidentiality of messages and barriers to understanding the messages, including the physical capacity to read and accurately interpret the content of the messaging.
\end{abstract}


Conclusions: Most participants indicated a willingness to receive text messages from their HCPs about cervical cancer screening results and believed that text messages were the best way to remind them of appointments for follow-up care. Potential concerns could be addressed by excluding explicit references to the nature of the appointment in the text message in order to avoid disclosure of sensitive health information to unauthorized individuals. Although text messaging seems promising to improve adherence to timely follow-up, personal preferences should be considered by allowing patients to opt-out of text communications.

(JMIR Form Res 2019;3(3):e12675) doi: 10.2196/12675

\section{KEYWORDS}

cervical cancer; Pap tests; abnormal results; text messaging; appointment reminders

\section{Introduction}

Cervical cancer mortality rates are significantly higher in African American/black women than any other racial or ethnic group in the United States [1,2]. This health disparity persists, especially in the South [3], despite evidence that black non-Hispanic woman participate in primary cervical cancer screening activities at approximately the same rates as white non-Hispanic women [4]. Regular cotesting with Pap tests (cytology) and oncogenic types of human papillomavirus (HPV), the virus that causes cervical cancer, is the primary screening method recommended to detect the presence of abnormal precancerous lesions [5].

In the United States, recommended follow-up for abnormal Pap results is completion of colposcopy with biopsy to confirm the presence of a high-grade lesion requiring treatment (cervical intraepithelial neoplasia, grade 2 or more severe, CIN2+), followed by treatment of CIN2+ through outpatient procedures such as loop electrosurgical excision procedure or cold cone biopsy [6]. Progression to invasive cervical cancer (ICC) can be prevented with the early detection of high-grade lesions and adherence to follow-up recommendations for further diagnostics and treatment [6]. Thus, the burden of cervical cancer could be significantly reduced through interventions that promote timely follow-up and treatment of women with abnormal Pap results [7].

Standard clinical protocols require that patients are notified of abnormal Pap results and referred to appropriate follow-up colposcopy and treatment procedures. However, multiple and complex factors may contribute to patient nonadherence to recommended follow-up once patients are informed of their abnormal screening results. These factors include patients' lack of the following factors: knowledge about HPV infection and cervical cancer [8], understanding about the seriousness of an abnormal Pap diagnosis [9], trust in health care providers (HCPs), health insurance, and family and social support [10,7]. Another important challenge is the inability to inform the patient of an abnormal result in a timely fashion due to a disconnected or changed phone number or an incorrect address to send or forward screening results [11]. Any one of these factors may lead a woman to miss or delay her follow-up care, increasing her chances of a poor clinical outcome.

Racial and ethnic differences have been observed in follow-up rates after an abnormal Pap test [12-15], in which African American and Hispanic women were less likely to schedule follow-up visits and receive follow-up care. In contrast, other studies have shown differences in follow-up rates between races to be negligible or even nonexistent [16]. It is imperative that women at the greatest risk of cervical cancer receive follow-up care after an abnormal Pap test or high-risk HPV test result to reduce cancer disparities. This can be achieved by increasing follow-up visits in this higher risk population [5].

The rapid expansion of mobile communications may present a low-cost opportunity to improve follow-up rates. Following an abnormal Pap test result, patients who receive a reminder via text message or short messaging service (SMS) may be more likely to attend a follow-up visit. SMS interventions have been shown to improve the rate of attendance at health care appointments for surveyed populations [17] and may have a similar impact as phone call and postal reminders [18-20]. With respect to cervical cancer, a prior study reported on the use of an SMS intervention to increase knowledge and encourage Pap test screening in Korean American [21] and African American women [22]. However, the feasibility of an SMS intervention to improve follow-up rates for in-clinic colposcopy attendance after an abnormal Pap test result has not been previously explored. For such an intervention to be successful among low-income and minority women, research is needed to understand appropriate SMS-based content, messaging, and context [23] and to determine the likelihood that such an approach would be acceptable to this population of patients.

Therefore, the objective of this study was to explore factors that may play a role in the use of text messaging as a mode to increase communications between HCPs among low-income and minority women who have undergone Pap tests as well as the need to return to the clinic to prevent potential advanced cancers.

\section{Methods}

\section{Study Design}

Participants were recruited from two clinics serving low-income and minority populations - a free community-based clinic and a university-based clinic - both of which are located in Durham, North Carolina. Women were eligible to participate in the study if they were between the ages of 21 and 60 years and had undergone a Pap test in the preceding 12 months. Participants were recruited by collaborating HCPs who provided eligible patients written information about the study and flyers with contact information at the time of their clinic appointment. Interested women signed forms giving permission for the research team to contact them and were contacted by phone for study enrollment. Due to challenges in successfully enrolling 
women through this process (eg, wrong telephone numbers, failure of participants to reply to messages, and difficulty scheduling appointments), the recruitment strategy was shifted to screen, enroll, and interview patients before or immediately after examination by the HCP, unless patients preferred to be contacted at a later time. The clinic provided a room where interviews could be conducted confidentially. This approach greatly reduced the loss between referral from the HCP and successful study completion within the allotted study period.

\section{Interviews}

After the participants completed an informed consent, semistructured interviews were conducted over the phone or in person, depending on the preference of the participant. The 58 -item interview guide included items from a review of the literature of SMS interventions and a validated questionnaire exploring attitudes and knowledge about HPV and cervical cancer. The combination of open- and closed-ended items included topics on overall attitudes of patients about text messaging practices, relationship with HCPs, preferences about clinic and appointment reminders, and knowledge about cervical cancer and HPV. Interviews were audio recorded and transcribed.

\section{Data Analyses}

Responses to closed-ended survey items were tabulated, and descriptive statistics were generated using Excel to report the demographic data, texting practices, and preferences variables. Responses to the open-ended questions were examined by two experienced qualitative researchers during four stages of analysis. As part of the first stage, transcripts were entered into
NVivo (version 11; NVivo qualitative data analysis software; QSR International Pty Ltd),

a qualitative software analysis package, and organized to allow each reader to efficiently access the same data while allowing for separate sets of analyses. Second, each reader independently read the original transcripts line by line to identify general themes or codes that emerged from the data using the memo functions and other tools of the software. Third, the readers compared their interpretations and refined themes that could be confirmed and systematically evidenced by the data. Fourth, the coders agreed on a final set of themes that appeared to be the most relevant to the study participants based on the frequency of appearance and richness of the evidence.

\section{Results}

\section{Participants}

The median age of the 15 participants was 34 years (range: 21-58 years). Most women were of African American race $(n=13,87 \%)$, had at least some college education $(n=10,57 \%)$, and were unemployed $(n=9,60 \%)$. In addition, a majority had health insurance $(n=10,67 \%)$, most through Medicaid, and nearly all owned a cell phone $(n=14,93 \%)$.

\section{Cell Phone Use}

Of the 14 women who own a cell phone, 13 (93\%) used text messaging, with some differences seen in the frequency of use according to age. All 10 women who had at least some college education (100\%) and most women with a high school degree or less education $(4 / 5,75 \%)$ used their cell phone to send text messages (Table 1). 
Table 1. Sociodemographic characteristics and cell phone utilization.

\begin{tabular}{|c|c|c|c|c|}
\hline Characteristic & Overall $(\mathrm{N}=15)$ & Age $<40$ years $(\mathrm{N}=8)$ & Age $\geq 40$ years $(N=7)$ & Fisher exact $P$ value \\
\hline Age (years), median (range) & $34(21-58)$ & $24(21-34)$ & $50(46-58)$ & $\mathrm{N} / \mathrm{A}^{\mathrm{a}}$ \\
\hline Race, $\mathrm{n}(\%)$ & & & & $>.99$ \\
\hline African American & $13(87)$ & $7(88)$ & $6(86)$ & \\
\hline White & $2(13)$ & $1(13)$ & $1(14)$ & \\
\hline Education, n (\%) & & & & $>.99$ \\
\hline Less than or high school degree & $5(33)$ & $3(38)$ & $2(29)$ & \\
\hline Some college/college degree & $10(57)$ & $5(63)$ & $5(71)$ & \\
\hline Employed, n (\%) & $6(40)$ & $4(50)$ & $2(29)$ & .61 \\
\hline Has health insurance, $\mathrm{n}(\%)$ & $10(67)$ & $5(63)$ & $5(71)$ & $>.99$ \\
\hline Owns a cell phone, n (\%) & $14(93)$ & $7(88)$ & $7(100)$ & $>.99$ \\
\hline Cell phone use per day, $n(\%)^{b}$ & & & & .001 \\
\hline$\leq 10$ & $6(43)$ & 0 & $6(86)$ & \\
\hline$>10$ & $8(57)$ & $7(100)$ & $1(14)$ & \\
\hline Text messages received per day, $n(\%)^{b}$ & & & & .20 \\
\hline$<25$ & $11(79)$ & $4(57)$ & $7(100)$ & \\
\hline$\geq 25$ & $3(21)$ & $3(43)$ & 0 & \\
\hline Text messages sent per day, $n(\%)^{c}$ & & & & .46 \\
\hline$<25$ & $11(85)$ & $5(71)$ & $6(100)$ & \\
\hline$\geq 25$ & $2(15)$ & $2(29)$ & $0(0)$ & \\
\hline \multicolumn{5}{|l|}{ Reported phone uses, $\mathrm{n}(\%)^{\mathrm{b}, \mathrm{d}}$} \\
\hline Send text messages & $13(93)$ & $7(100)$ & $6(86)$ & $>.99$ \\
\hline Find directions & $10(71)$ & $6(86)$ & $4(57)$ & .56 \\
\hline Take photos & $13(93)$ & $7(100)$ & $6(86)$ & $>.99$ \\
\hline Check Facebook or Twitter & $10(71)$ & $7(100)$ & $3(43)$ & .07 \\
\hline
\end{tabular}

${ }^{\mathrm{a}} \mathrm{N} / \mathrm{A}$ : not applicable.

${ }^{b} \mathrm{~N}=14$ women who owned a cell phone ( $\mathrm{n}=7$ for women aged $<40$ years and $\mathrm{n}=7$ for women aged $\geq 40$ years).

${ }^{c} \mathrm{~N}=13$, missing one response ( $\mathrm{n}=7$ for women aged $<40$ years and $\mathrm{n}=6$ for women aged $\geq 40$ years).

${ }^{\mathrm{d}}$ More than one choice could be selected.

\section{Communication Preferences}

Most women $(n=14,93 \%)$ indicated that they were comfortable receiving text messages from their HCPs following primary screening visits. Nearly all women in the study $(n=14,93 \%)$ were comfortable receiving a text message from an HCP, stating that their Pap test results are available. However, $75 \%(6 / 8)$ of women aged $<40$ years and only $29 \%$ (2/7) of women aged $\geq 40$ years were comfortable receiving a text message stating that their Pap test results were abnormal (Table 2).

When offered a list of preferences for receiving information about their abnormal Pap test results (including via phone, text, letter, or some other way), 6 (43\%) of the 14 participants who owned cell phones preferred to receive this information by phone, 2 (14\%) preferred text, and 6(43\%) stated no preference.

Nearly half $(7 / 15,47 \%)$ of all participating women were comfortable receiving a reminder via phone to come back to the clinic for follow-up care after an abnormal Pap test, and $33 \%$ were comfortable receiving a reminder by text message. Most participants $(13 / 15,87 \%)$ indicated that if they received a text message from the clinic, they would be willing to respond to indicate that they had received the message (Table 2). 
Table 2. Women's communication preferences for test results overall and stratified by age. No significant relationships were found (using the Fisher exact test).

\begin{tabular}{|c|c|c|c|c|}
\hline Preference & $\begin{array}{l}\text { Overall }(\mathrm{N}=15) \\
\mathrm{n}(\%)\end{array}$ & $\begin{array}{l}\text { Age }<40 \text { years }(\mathrm{n}=8) \\
\mathrm{n}(\%)\end{array}$ & $\begin{array}{l}\text { Age } \geq 40 \text { years }(\mathrm{n}=7) \\
\mathrm{n}(\%)\end{array}$ & Fisher exact $P$ value \\
\hline \multicolumn{5}{|c|}{ Comfortable receiving information that lab test results are available through: } \\
\hline Phone message & $15(100)$ & $8(100)$ & $7(100)$ & $>.99$ \\
\hline Text message & $13(87)$ & $8(100)$ & $5(83)$ & .20 \\
\hline \multicolumn{5}{|c|}{ Comfortable receiving a text message from a health care provider stating that Pap test results are: } \\
\hline Available & $14(93)$ & $8(100)$ & $6(86)$ & .47 \\
\hline Abnormal & $8(53)$ & $6(75)$ & $2(29)$ & .13 \\
\hline $\begin{array}{l}\text { Willing to respond to indicate that you had received a text } \\
\text { message from the clinic }\end{array}$ & $13(87)$ & $8(100)$ & $5(71)$ & .20 \\
\hline
\end{tabular}

\section{Attitudes About Communication Preferences}

Analysis of open-ended questions provided useful details on the benefits and barriers to using text messaging for communicating with HCPs, receiving test results, and receiving follow-up visit reminders (Table 3). Cited advantages of text messaging included ease of use and convenience, especially to receive notifications. For some women, texting was no different than the current common practice of providing appointment reminders by phone. However, several participants (particularly older participants) reported barriers to text messaging, including inconvenience (it is easier to call), lack of texting proficiency (not comfortable with texting, texting too slowly, or technologically challenged), difficulty in texting (diminished physical ability), and a lack of confidence in their ability to correctly understand and interpret the content of the text message (often due to low literacy). Some participants felt that the text message would be useless because they generally ignore unsolicited text messages from a source unknown to them.

Most participants also reported concerns over privacy and confidentiality of health information communicated by text, such as receiving a notification for a positive Pap test or for a follow-up visit after a positive Pap test. Most participants were concerned that family members, friends, coworkers, or strangers could gain access to personal health information if the phone was lost or left unattended or was used by others (eg, some participants share their phone with family members). Some participants were also concerned about the potential of hackers accessing their private health information. When probed to explore what might allay their privacy concerns, participants seemed open to discussing strategies such as encryption or passwords, although some still expressed skepticism about the ability of the clinic to safeguard the information.

Table 3. Emergent themes: attitudes about receiving text message reminders to return to the clinic to follow-up on abnormal cervical cancer test results.

\begin{tabular}{|c|c|}
\hline Theme & Response \\
\hline \multicolumn{2}{|l|}{ Benefits } \\
\hline Convenience & $\begin{array}{l}\text { "Text just makes it easier to check and see, and then it would be helpful if the text contained a number to call back." } \\
{\left[\mathrm{P}^{\mathrm{a}} 14\right]}\end{array}$ \\
\hline Notification & "It's impersonal, but just to text me to inform me to come in or your results is back, that's notification." [P7] \\
\hline \multicolumn{2}{|l|}{ Barriers } \\
\hline \multirow[t]{2}{*}{$\begin{array}{l}\text { Capacity to text (knowledge, } \\
\text { comfort, and ability) }\end{array}$} & $\begin{array}{l}\text { "It's a lot of text messages on here, but I don't know how to pull it up on my phone. I just don't know how to do } \\
\text { it." [P9] }\end{array}$ \\
\hline & $\begin{array}{l}\text { "I'm not a text person myself. To me - texting is for the younger generation. It takes more time to text than to just } \\
\text { call." [P3] }\end{array}$ \\
\hline Physical limitations & $\begin{array}{l}\text { "My hand get tired and I have carpal tunnel so I don't mess with it...And then I have arthritis in my hands too, so } \\
\text { can't do that..." [P3] }\end{array}$ \\
\hline Trust & $\begin{array}{l}\text { "I have seen some messages about different things but like I said, if it was unsolicited, I didn't pay it any attention." } \\
\text { [P10] }\end{array}$ \\
\hline \multirow[t]{3}{*}{ Confidentiality and privacy } & $\begin{array}{l}\text { "Let's say for example, I leave my phone sitting right here and I go to the bathroom, then all of a sudden, they de- } \\
\text { cided to text me and the text is gonna show up on my phone." [P10] }\end{array}$ \\
\hline & "Some people don't have a lock on their phone like I don't have a lock on my phone.” [P12] \\
\hline & $\begin{array}{l}\text { "It's hackers out there and...they go into you medical history and they can pull it up and see everything right there } \\
\text { on the phone." [P8] }\end{array}$ \\
\hline
\end{tabular}

${ }^{\mathrm{a} P}$ : participant. 


\section{Discussion}

In this study, we determined the feasibility and acceptability of using text messaging to improve abnormal Pap test follow-up in minority and medically underserved women in North Carolina. Overall, most respondents seemed receptive to text messaging reminders from their health care providers. Most participants were open to receiving text message notifications that their tests results were available as well as text message reminders about the need to come back to the clinic for follow-up appointments. More respondents preferred receiving abnormal Pap test results by phone rather than by text, although a large proportion reported no preference.

Although most participants reported finding text messaging easy to use and convenient, some participants reported barriers to using text messages (such as comfort, knowledge, and literacy) and concerns about the confidentiality of their private health information. To address issues of confidentiality, clinics could minimize details in the message about the nature of the test results or appointment. Personal preferences should be considered in the use of this technology by allowing patients to opt-out of text communications. Incorrect contact information is a challenge for health care institutions to ensure adequate follow-up, which might be addressed by verbal communication or text message confirmation of the correct number while the patient is still at the clinic for her screening appointment.

A strength of this study lies in the use of open-ended and closed-ended items, which allowed the researchers to both determine the proportion of particular attitudes and collect more detailed information on the benefits of using text messaging to increase compliance with HCP instructions and guidelines as well as the challenges and barriers that may need to be overcome to maximize the use of this technology in this population. Many cognitive and personal factors are associated with failure to comply with recommended follow-up on abnormal results [9-11], which represent broader contextual issues for consideration. For example, one limitation of this study is that we did not systematically collect data on previous experience with abnormal Pap results to assess how these experiences might affect current attitudes.

This study has other limitations. First, due to the small sample size and the nature of the population enrolled (majority of minority and medically underserved women in North Carolina), participants' opinions collected in this study may not reflect those of a broader population. Second, although the focus of the study was to determine the acceptability of text messaging among women who had already undergone primary screening, the importance attributed to the use of all mobile phone apps, including social media platforms (ie, Facebook) particularly for younger women who are more accustomed to these technologies, was not examined. Third, further research is needed to study the effects of such apps on secondary and tertiary prevention activities.

Successful follow-up care and treatment of women with abnormal Pap test results are important for preventing ICC. Reminders are useful tools, which have shown to improve regular screening practices and may allow health care providers to improve adherence to follow-up recommendations. Mobile phones are ubiquitous and provide a convenient and low-cost approach to improve adherence rates. Further research in an actual intervention study is needed to assess the feasibility and effectiveness of SMS approaches to improve adherence to follow-up care among high-risk women with abnormal cervical cancer screening results. A trial is in development to evaluate the effect of a text message intervention on increasing follow-up completion.

\section{Acknowledgments}

We would like to extend our deep gratitude to Dr Sharon Bynum-Elliott who passed away before the publication of this manuscript and to her entire team for their assistance and participation and most of all dedication to the women who participated in this study. The project described was supported by NCCU-LCCC Partnership in Cancer Research (5 U54CA156733 and U54CA156735) from the National Cancer Institute. The content is solely the responsibility of the authors and does not necessarily represent the official views of the National Cancer Institute or the National Institutes of Health.

\section{Conflicts of Interest}

None declared.

\section{References}

1. Noone A, Howlader N, Krapcho M, Miller D, Brest A, Yu M, et al. SEER Cancer Statistics Review, 1975-2015. Bethesda, MD: National Cancer Institute; 2018 Nov 02. URL: https://seer.cancer.gov/csr/1975 2015/ [accessed 2018-11-02] [WebCite Cache ID 73dKpbaTD]

2. Benard VB, Watson M, Saraiya M, Harewood R, Townsend JS, Stroup AM, et al. Cervical cancer survival in the United States by race and stage (2001-2009): Findings from the CONCORD-2 study. Cancer 2017 Dec 15;123 Suppl 24:5119-5137. [doi: 10.1002/cncr.30906] [Medline: 29205300]

3. Yoo W, Kim S, Huh WK, Dilley S, Coughlin SS, Partridge EE, et al. Recent trends in racial and regional disparities in cervical cancer incidence and mortality in United States. PLoS One 2017;12(2):e0172548 [FREE Full text] [doi: 10.1371/journal.pone.0172548] [Medline: 28234949] 
4. Wharam JF, Zhang F, Xu X, Landon BE, Ross-Degnan D. National trends and disparities in cervical cancer screening among commercially insured Women, 2001-2010. Cancer Epidemiol Biomarkers Prev 2014 Nov;23(11):2366-2373 [FREE Full text] [doi: 10.1158/1055-9965.EPI-13-1202] [Medline: 25128400]

5. Schlichte MJ, Guidry J. Current Cervical Carcinoma Screening Guidelines. J Clin Med 2015 May 07;4(5):918-932 [FREE Full text] [doi: 10.3390/jcm4050918] [Medline: 26239455]

6. Saslow D, Solomon D, Lawson HW, Killackey M, Kulasingam SL, Cain JM, et al. American Cancer Society, American Society for Colposcopy and Cervical Pathology, and American Society for Clinical Pathology screening guidelines for the prevention and early detection of cervical cancer. J Low Genit Tract Dis 2012 Jul;16(3):175-204 [FREE Full text] [doi: 10.1097/LGT.0b013e31824ca9d5] [Medline: 22418039]

7. Zapka J, Taplin SH, Price RA, Cranos C, Yabroff R. Factors in quality care--the case of follow-up to abnormal cancer screening tests--problems in the steps and interfaces of care. J Natl Cancer Inst Monogr 2010;2010(40):58-71 [FREE Full text] [doi: 10.1093/jncimonographs/lgq009] [Medline: 20386054]

8. Strohl AE, Mendoza G, Ghant MS, Cameron KA, Simon MA, Schink JC, et al. Barriers to prevention: knowledge of HPV, cervical cancer, and HPV vaccinations among African American women. Am J Obstet Gynecol 2015 Jan;212(1):65.e1-65.e5 [FREE Full text] [doi: 10.1016/j.ajog.2014.06.059] [Medline: 24983684]

9. Fish LJ, Moorman PG, Wordlaw-Stintson L, Vidal A, Smith JS, Hoyo C. Factors Associated With Adherence to Follow-up Colposcopy. Am J Health Educ 2013;44(6):293-298 [FREE Full text] [doi: 10.1080/19325037.2013.838881] [Medline: 24991653]

10. Tejeda S, Darnell JS, Cho YI, Stolley MR, Markossian TW, Calhoun EA. Patient barriers to follow-up care for breast and cervical cancer abnormalities. J Womens Health (Larchmt) 2013 Jun;22(6):507-517 [FREE Full text] [doi: 10.1089/jwh.2012.3590] [Medline: 23672296]

11. Wordlaw-Stinson L, Jones S, Little S, Fish L, Vidal A, Smith JS, et al. Challenges and Recommendations to Recruiting Women Who Do Not Adhere to Follow-Up Gynecological Care. Open J Prev Med 2014 Mar 20;4(3):123-128 [FREE Full text] [doi: 10.4236/ojpm.2014.43017] [Medline: 24991485]

12. Cardin VA, Grimes RM, Jiang ZD, Pomeroy N, Harrell L, Cano P. Low-income minority women at risk for cervical cancer: a process to improve adherence to follow-up recommendations. Public Health Rep 2001;116(6):608-616 [FREE Full text] [doi: $10.1093 / \mathrm{phr} / 116.6 .608]$ [Medline: 12196621$]$

13. Duggan C, Coronado G, Martinez J, Byrd TL, Carosso E, Lopez C, et al. Cervical cancer screening and adherence to follow-up among Hispanic women study protocol: a randomized controlled trial to increase the uptake of cervical cancer screening in Hispanic women. BMC Cancer 2012 May 06;12:170 [FREE Full text] [doi: 10.1186/1471-2407-12-170] [Medline: 22559251]

14. Engelstad LP, Stewart SL, Nguyen BH, Bedeian KL, Rubin MM, Pasick RJ, et al. Abnormal Pap smear follow-up in a high-risk population. Cancer Epidemiol Biomarkers Prev 2001 Oct;10(10):1015-1020 [FREE Full text] [Medline: 11588126]

15. Miller SM, Siejak KK, Schroeder CM, Lerman C, Hernandez E, Helm CW. Enhancing adherence following abnormal Pap smears among low-income minority women: a preventive telephone counseling strategy. J Natl Cancer Inst 1997 May 21;89(10):703-708. [Medline: 9168185]

16. Eggleston KS, Coker AL, Luchok KJ, Meyer TE. Adherence to recommendations for follow-up to abnormal Pap tests. Obstet Gynecol 2007 Jun;109(6):1332-1341. [doi: 10.1097/01.AOG.0000266396.25244.68] [Medline: 17540805]

17. Ganta V, Moonie S, Patel D, Hunt AT, Richardson J, Di John D, et al. Timely reminder interventions to improve annual Papanicolaou (Pap) smear rates among HIV-infected women in an outpatient center of southern Nevada: a short report. AIDS Care 2017 Dec;29(9):1099-1101. [doi: 10.1080/09540121.2017.1322677] [Medline: 28460538]

18. Junod PN, Dao MD, Righini NC, Humair J, Broers B, Narring F, et al. Text-messaging versus telephone reminders to reduce missed appointments in an academic primary care clinic: a randomized controlled trial. BMC Health Serv Res 2013;13:125 [FREE Full text] [doi: 10.1186/1472-6963-13-125] [Medline: 23557331]

19. Uy C, Lopez J, Trinh-Shevrin C, Kwon SC, Sherman SE, Liang PS. Text Messaging Interventions on Cancer Screening Rates: A Systematic Review. J Med Internet Res 2017 Aug 24;19(8):e296 [FREE Full text] [doi: 10.2196/jmir.7893] [Medline: 28838885]

20. Miller SM, Hui SA, Wen K, Scarpato J, Zhu F, Buzaglo J, et al. Tailored telephone counseling to improve adherence to follow-up regimens after an abnormal pap smear among minority, underserved women. Patient Educ Couns 2013 Dec;93(3):488-495 [FREE Full text] [doi: 10.1016/j.pec.2013.08.008] [Medline: 24007767]

21. Lee HY, Koopmeiners JS, Rhee TG, Raveis VH, Ahluwalia JS. Mobile phone text messaging intervention for cervical cancer screening: changes in knowledge and behavior pre-post intervention. J Med Internet Res 2014;16(8):e196 [FREE Full text] [doi: 10.2196/jmir.3576] [Medline: 25164545]

22. Schoenberger Y, Phillips J, Mohiuddin MO, McNees P, Scarinci I. Acceptability of delivering and accessing health information through text messaging among community health advisors. JMIR Mhealth Uhealth 2013;1(2):e22 [FREE Full text] [doi: 10.2196/mhealth.2641] [Medline: 25099140]

23. Le D, Aldoory L, Garza MA, Fryer CS, Sawyer R, Holt CL. A Spiritually-Based Text Messaging Program to Increase Cervical Cancer Awareness Among African American Women: Design and Development of the CervixCheck Pilot Study. JMIR Formativ Res 2018 Mar 29;2(1):e5. [doi: 10.2196/formative.8112] 


\title{
Abbreviations \\ HCP: health care providers \\ HPV: human papillomavirus \\ ICC: invasive cervical cancer \\ SMS: short messaging service
}

\author{
Edited by $G$ Eysenbach; submitted 07.11.18; peer-reviewed by KY Wen, $R$ Catarino; comments to author 05.04.19; revised version \\ received 24.05.19; accepted 25.05.19; published 06.08.19 \\ Please cite as: \\ Romocki LS, Des Marais A, Cofie L, Anderson C, Curington T, Smith JS \\ Use of Short Messaging Service to Improve Follow-Up for Abnormal Pap Test Results in Minority and Medically Underserved Women \\ in North Carolina: Questionnaire on Attitudes and Acceptability \\ JMIR Form Res 2019;3(3):e12675 \\ URL: https://formative.jmir.org/2019/3/e12675/ \\ doi: $\underline{10.2196 / 12675}$ \\ PMID: 31389334
}

CLaHoma Smith Romocki, Andrea Des Marais, Leslie Cofie, Chelsea Anderson, Theresa Curington, Jennifer Susan Smith. Originally published in JMIR Formative Research (http://formative.jmir.org), 06.08.2019. This is an open-access article distributed under the terms of the Creative Commons Attribution License (https://creativecommons.org/licenses/by/4.0/), which permits unrestricted use, distribution, and reproduction in any medium, provided the original work, first published in JMIR Formative Research, is properly cited. The complete bibliographic information, a link to the original publication on http://formative.jmir.org, as well as this copyright and license information must be included. 